nos. EPI_ISL_632934 and EPI_ISL_632935. Sequence alignment analyses (4) revealed that the 2SARS-CoV-2 sequences from Ruili shared 13 mutations: C241T, C3037T, G11083T, C14408T, G18756T, C18877T, C22444T, A23403G, G25494T, G25563T, C26735T, C28854T, and G29737C (Appendix Figure 2) $(5,6)$. According to the Pangolin COVID-19 Lineage Assigner (7), 9 of these mutations (i.e., C241T, C3037T, C14408T, C18877T, C22444T, A23403G, G25563T, C26735T, and C28854T) indicate membership in the B.1.36 clade of SARS-CoV-2. Further phylogenetic analyses supported this conclusion (Appendix Table 2, Figure 3). Compared with sequences from earlier COVID-19 outbreaks in Beijing Xinfadi Market (1,8), Dalian (9), and Qingdao, the Ruili sequences had 7 previously unreported mutations (Appendix Figure 2, panel B) (5). The Ruili cases were not associated with the mentioned outbreaks and were probably imported.

Although the SARS-CoV-2-infected migrants did not cause a COVID-19 outbreak, the event illustrates a transmission pathway distinct from air travel and cold-chain food transmission (1). The International Health Regulations and World Health Organization encourage open borders and suggest that COVID-19 control measures be applied only in limited circumstances (10). In 2020, official land ports in Yunnan Province did not close for the COVID-19 pandemic. Because of the long international border, epidemic control remains challenging in this province. Governments should control illegal immigration to avoid future reintroductions of COVID-19. Regional guidelines for COVID-19 control and prevention should strengthen surveillance of undocumented movement across borders, especially from neighboring countries with high rates of infection.

\section{Acknowledgments}

We are grateful to the health workers who contributed to this epidemiologic survey. We thank the staff at Ruili People's Hospital for sample collection and transportation.

\section{About the Author}

Dr. Zhang is a supervising technician at Yunnan Provincial Center for Disease Control and Prevention, Kunming,
China. Her research interests include viral genomics research associated with infectious diseases.

\section{References}

1. Pang X, Ren L, Wu S, Ma W, Yang J, Di L, et al. Cold-chain food contamination as the possible origin of Covid-19 resurgence in Beijing. Natl Sci Rev. 2020;7:1861-4. https:/ / doi.org/10.1093/nsr/nwaa264

2. Choi B, Choudhary MC, Regan J, Sparks JA, Padera RF, Qiu X, et al. Persistence and evolution of SARS-CoV-2 in an immunocompromised host. N Engl J Med. 2020;383:2291-3. https:/ / doi.org/10.1056/NEJMc2031364

3. Paden CR, Tao Y, Queen K, Zhang J, Li Y, Uehara A, et al. Rapid, sensitive, full-genome sequencing of severe acute respiratory syndrome coronavirus 2. Emerg Infect Dis. 2020;26:2401-5. https://doi.org/10.3201/eid2610.201800

4. Katoh K, Misawa K, Kuma K, Miyata T. MAFFT: a novel method for rapid multiple sequence alignment based on fast Fourier transform. Nucleic Acids Res. 2002;30:3059-66. https://doi.org/10.1093/nar/gkf436

5. Mercatelli D, Giorgi FM. Geographic and genomic distribution of SARS-CoV-2 mutations. Front Microbiol. 2020;11:1800. https://doi.org/10.3389/fmicb.2020.01800

6. Rahimi A, Mirzazadeh A, Tavakolpour S. Genetics and genomics of SARS-CoV-2: a review of the literature with the special focus on genetic diversity and SARS-CoV-2 genome detection. Genomics. 2021;113:1221-32. https://doi.org/10.1016/j.ygeno.2020.09.059

7. Rambaut A, Holmes EC, O'Toole Á, Hill V, McCrone JT, Ruis C, et al. A dynamic nomenclature proposal for SARS$\mathrm{CoV}-2$ lineages to assist genomic epidemiology. Nat Microbiol. 2020;5:1403-7. https://doi.org/10.1038/ s41564-020-0770-5

8. Wenjie T, Peihua N, Xiang Z, Yang P, Yong Z, Lijuan C, et al. Reemergent cases of COVID-19 - Xinfadi Wholesales Market, Beijing Municipality, China, June 11, 2020. China CDC Weekly. 2020;2:502-4. https://doi.org/10.46234/ ccdcw2020.132

9. Zhao X, Mao L, Zhang J, Zhang Y, Song Y, Bo Z, et al. Reemergent cases of COVID-19 - Dalian City, Liaoning Province, China, July 22, 2020. China CDC Weekly. 2020;2:658-60. https:// doi.org/10.46234/ccdcw2020.182

10. Ferhani A, Rushton S. The International Health Regulations, COVID-19, and bordering practices: who gets in, what gets out, and who gets rescued? Contemp Secur Policy. 2020;41:458-77. https://doi.org/10.1080/13523260.2020.177 1955

Address for correspondence: Meiling Zhang, Yunnan Center for Disease Control and Prevention, 158 Dongsi St, Xishan District, Kunming 650022, China; email: meilingz2011@163.com; Yong Shao, Kunming Institute of Zoology, 17 Longxin Rd, Panlong District, Kunming 650203, China; email: shaoyong@mail.kiz.ac.cn

\title{
Correction: Vol. 27, No. 3
}

The order of the authors was incorrect for Drug-Resistant Tuberculosis in Pet Ring-Tailed Lemur, Madagascar (M. LaFleur et al.). The article has been corrected online (https://wwwnc.cdc.gov/eid/article/27/3/20-2924_article). 